\title{
Data Collection Plan to Populate the Light Water Reactor Sustainability Failure Mode Degradation Library
}

Magdy S. Tawfik Binh T. Pham Vivek Agarwal Nancy J. Lybeck

September 2011

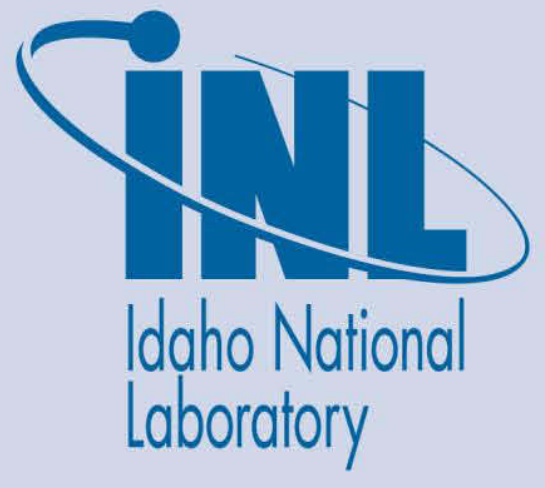

The INL is a U.S. Department of Energy National Laboratory operated by Battelle Energy Alliance 


\section{DISCLAIMER}

This information was prepared as an account of work sponsored by an agency of the U.S. Government. Neither the U.S. Government nor any agency thereof, nor any of their employees, makes any warranty, expressed or implied, or assumes any legal liability or responsibility for the accuracy, completeness, or usefulness, of any information, apparatus, product, or process disclosed, or represents that its use would not infringe privately owned rights. References herein to any specific commercial product, process, or service by trade name, trade mark, manufacturer, or otherwise, does not necessarily constitute or imply its endorsement, recommendation, or favoring by the U.S. Government or any agency thereof. The views and opinions of authors expressed herein do not necessarily state or reflect those of the U.S. Government or any agency thereof. 


\title{
Data Collection Plan to Populate the Light Water Reactor Sustainability Failure Mode Degradation Library
}

\author{
Magdy S. Tawfik \\ Binh T. Pham \\ Vivek Agarwal \\ Nancy J. Lybeck
}

September 2011

Idaho National Laboratory

Idaho Falls, Idaho 83415

http://www.inl.gov

Prepared under Work Package L-11N060201

Prepared for the

U.S. Department of Energy

Office of Nuclear Energy

Under DOE Idaho Operations Office

Contract DE-AC07-05ID14517 


\begin{abstract}
Interest in implementing advanced prognostic health management (PHM) systems in commercial nuclear power plants (NPPs) has increased rapidly in recent years, with an overarching goal of improving the safety, reliability, and economics/profitability of the aging nuclear fleet and extending their service life in the most cost-effective manner. The PHM system utilizes prognostic tools to estimate the remaining useful life (RUL) of a component or system of components based on current and predicted operating conditions. An effective implementation of the PHM system will anticipate and identify unique agedependent degradation modes to provide early warning of emerging problems. Selection of the components and structures to be monitored is a crucial step for successful PHM implementation in NPPs. A selection framework is recommended for risk significant components (both safety-related and non-safety related) based on the Fussell-Vesely (F-V) Importance Measure and the risk achievement worth (RAW) measure. For the selected components, a failure mode degradation library will be developed consisting of data corresponding to different failure or degradation modes. In lieu of constructing an expensive scaled test facility, several data sources are identified for populating the failure mode degradation library, including various national laboratories, universities, agencies, and industries.
\end{abstract}




\section{CONTENTS}

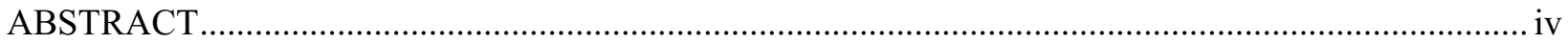

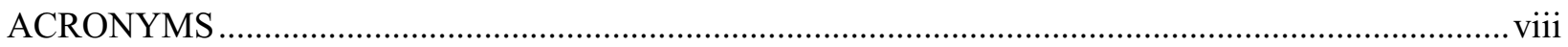

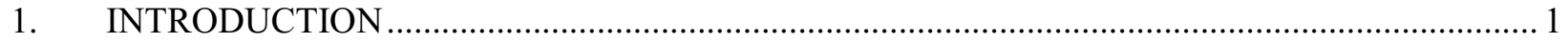

2. COMPONENT SELECTION FOR ONLINE MONITORING SYSTEM................................... 2

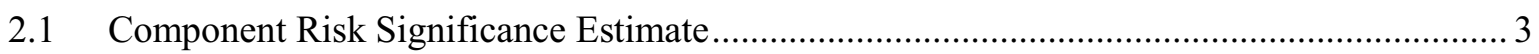

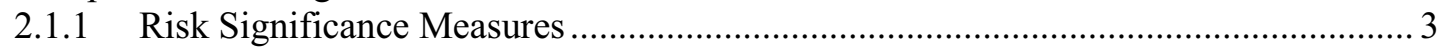

2.1.2 Risk Significant Estimation Methods.................................................................. 4

2.1.3 Limitations of component risk significance measures ........................................... 4

2.2 Limitations of Traditional Maintenance and Monitoring Approaches................................... 4

2.3 Risk-Informed Performance-based Maintenance ................................................................ 5

2.4 Prognostic and Health Monitoring (PHM) Maintenance Strategy ….................................... 5

2.5 Component Selection for Advanced PHM System ............................................................. 6

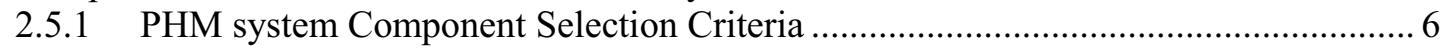

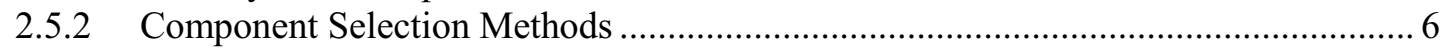

2.5.3 Component Risk Significance Measure Estimation.............................................. 7

2.5.4 Assessment of the Economic Benefit of the Proposed PHM System ........................ 7

3. DIAGNOSIS AND PROGNOSIS TEST FACILITIES AND DATA REPOSITORIES ................. 12

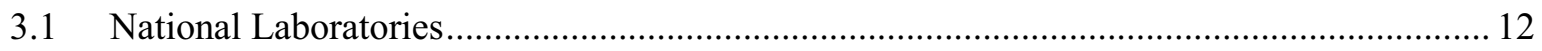

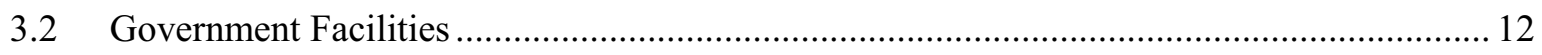

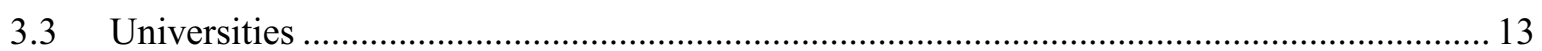

3.3.1 Pennsylvania State University Applied Research Laboratory ............................... 13

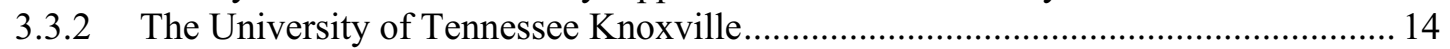

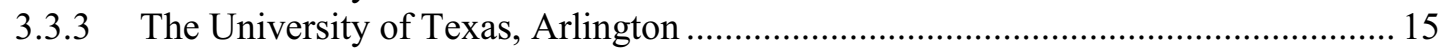

3.3.4 Georgia Technical University: System Monitoring and Prognostic Lab .................. 15

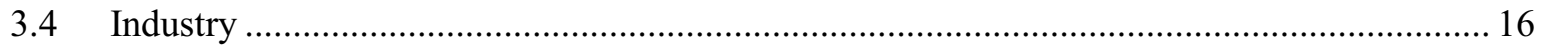

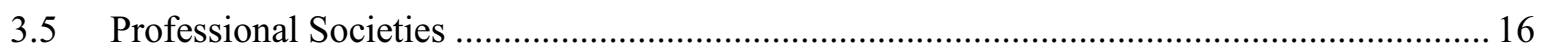

3.5.1 Prognostic and Health Monitoring Society (PHM Society) .................................... 16

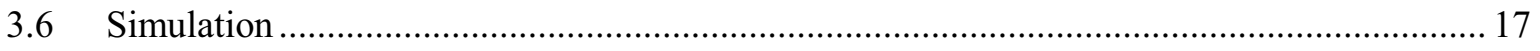

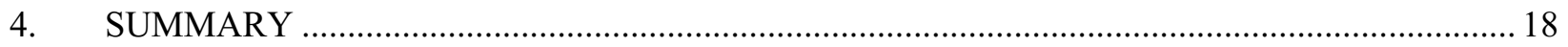

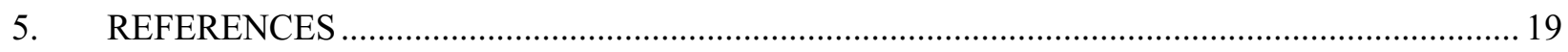




\section{FIGURES}

Figure 1. Outcome of component selection decision for implementation of PHM system based on

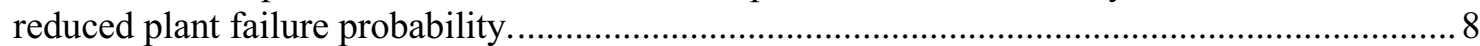

Figure 2. Bearing test rig and sensor placement illustration............................................................... 13

Figure 3. Pump Loop Facility at Pennsylvania State University. ........................................................... 13

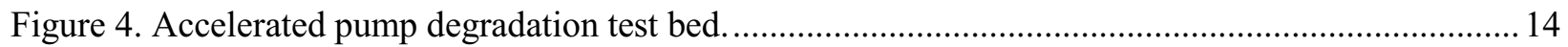

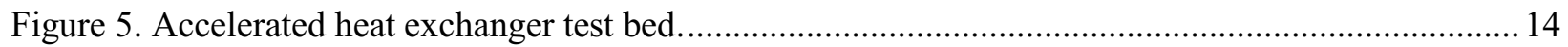

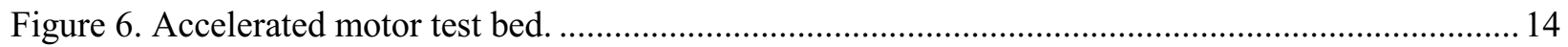

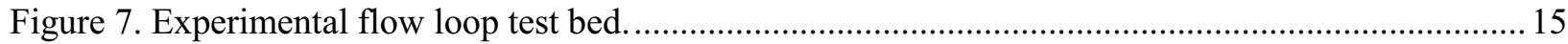

Figure 8. Bearing testing setup to emulate degradation in rotating machinery....................................... 16

Figure 9. Experimental setup for gearbox degradation testing. .......................................................... 17

Figure 10. An example of gear faults. Left to right: normal, missing tooth, and chipped tooth................ 17

\section{TABLES}

Table 1. Categorization of NPP SSCs based on risk significance measures and safety status. 


\section{ACRONYMS}

ADAPT Advanced Diagnostics and Prognostics Test

AFS Asset Fault Signature

ARL Applied Research Laboratory

CDF Core Damage Frequency

ECCS Emergency Core Cooling System

EPRI Electric Power Research Institute

F-V Fussell-Vesely

HFIR High Flux Isotope Reactor

HPCS High Pressure Core Spray

I\&C Instrumentation and Control

ICP Integrated Circuit Piezoelectric

IMS Intelligent Maintenance System

INL Idaho National Laboratory

IPE Individual Plant Examination

IRIS International Reactor Secure and Innovative

I/UCR Industry/University Cooperative Research

LERF Large Early Release Frequency

LOCA Loss of Coolant Accident

LWRS Light Water Reactor Sustainability

MSPI Mitigating Systems Performance Index

NASA National Aeronautics and Space Administration

NEER Nuclear Engineering Education Research

NEI Nuclear Energy Institute

NERI-C Nuclear Energy Research Initiative Consortia

NPP Nuclear Power Plants

NSF National Science Foundation

NUMARC Nuclear Management and Resources Council

O\&M Operations and Maintenance

ORNL Oak Ridge National Laboratory

PHM Prognostic Health Management

PM Preventive Maintenance

PNNL Pacific Northwest National Laboratory

PRA Probabilistic Risk Assessment 
PSD Power Spectral Density

RAW Risk Achievement Worth

RBPI Risk-Based Performance Indicator

RHR Residual Heat Remover

RUL Remaining Useful Life

SAPHIRE Systems Analysis Programs for Hands-on Integrated Reliability Evaluations

SBIR Small Business Innovation Research

SSC Structure, System, and Component 


\section{Data Collection Plan to Populate the Light Water Reactor Sustainability Failure Mode Degradation Library}

\section{INTRODUCTION}

Advanced prognostic health monitoring (PHM) systems are expected to play an important role in current efforts to extend the operational lifetime of the aging fleet of U.S. nuclear power plants (NPPs) from 40 to 60 years and beyond. A complete PHM system uses online monitoring along with diagnostic and prognostic techniques to anticipate, identify, classify, and mitigate problems with structures, systems, and components (SSCs). Prognostic tools can play a vital role in increasing plant safety and efficiency, avoiding accidents, and reducing downtime and maintenance costs. A current state-of-the art online monitoring system can be enhanced using advanced diagnostic and prognostic tools to provide early warning of degradation and to identify unique age-related degradation signatures and fault progression in interconnected components.

NPPs rely on a large number of pumps, valves, circuit breakers, and other mechanical, electrical, and instrumentation and control equipment to operate safely, reliably, and cost-effectively. The first step toward implementation of the PHM system in an NPP requires careful selection of SSCs. The selection of components to be monitored using the PHM system is based on the risk significance of a component; expected mode(s) of degradation; current operating and maintenance procedures; and costs. The risk significant SSCs are divided into two categories: (1) safety-related SSCs; and (2) non-safety related SSCs. The two standard measures adopted here to quantify the risk significance for each SSC (both safety related and non-safety related) are the Fussell-Vesely (F-V) Importance Measure and the risk achievement worth (RAW).

The second step toward implementation of the PHM system in an NPP is to gather relevant data for the selected SSCs from all available sources. Large amounts of high-fidelity physical data covering the full range of operating conditions for both healthy and faulted components are necessary to develop, validate and calibrate both diagnostic and prognostic models. Plants currently equipped with an online monitoring system are ideal sources for such data.

Failure signatures and precursor informational data are often difficult to obtain in high-risk environments like NPPs, as critical components are replaced on a conservative time-based approach in order to prevent failure. This provides motivation to build a scaled test facility at Idaho National Laboratory (INL) to collect data for faulted components and to establish an optimal predictive maintenance program for selected risk significant SSCs. Data collected for different failure modes would be used: (1) to develop a failure mode degradation library; and (2) to demonstrate the implementation of PHM system.

Due to fiscal constraints, building a scaled test facility is an infeasible option in the near future. In lieu of collecting data at INL, relevant sources of data have been identified at various national laboratories, universities, agencies, and industries. Even in a laboratory situation, it will likely be difficult to collect sufficient operational data for all anticipated failure modes. Commercial software packages have also been identified that can be used to fill in the data gaps with simulated failure data. 


\section{COMPONENT SELECTION FOR ONLINE MONITORING SYSTEM}

Nuclear power plants rely on a large number of pumps, valves, circuit breakers, and other mechanical, electrical, and instrumentation and control equipment to operate safely, reliably, and cost-effectively. Equipment reliability depends on carefully designed operations, maintenance, repair, and replacement practices, coupled with properly trained plant personnel.

The SSCs in NPPs are any piece of equipment or collection of equipment that is configured and operated to serve some specific plant function (e.g., provides water to the steam generators, sprays water into the containment, and injects water into the primary system), as defined by the terminology of each utility (e.g., auxiliary feed water system, containment spray system, high pressure coolant injection system).

The aim of NPP operation and maintenance management is to maintain an adequate overall safety level (or safety margins) and maximize long-term profitability of the power production throughout the lifetime of a plant. The power reactor utilities are required to monitor the performance and/or condition of SSCs against established goals in a manner sufficient to provide reasonable assurance that the SSCs are capable of fulfilling their intended functions. Such goals are established commensurate with safety and, where practical, take into account industry-wide operating experience. When the performance or condition of an SSC does not meet established goals, appropriate corrective action must be taken. The need for implementation of advanced PHM systems in nuclear industry is extensively addressed in various studies. ${ }^{1,2,3}$

The implementation of an advanced PHM system is aimed at: (1) strengthening the existing safety systems in NPPs, (2) providing early warning of degrading SSCs; and (3) reducing the utility's operations and maintenance (O\&M) costs by utilizing new sensing, monitoring, diagnostic, and prognostic technologies. PHM systems provide timely plant-specific component operating reliability needed for optimizing tests and enhancing maintenance activity planning. Accurate component health assessment (degradation state information) allows in-time performance-based inspection, test, and repair, thereby reducing component failure probability and reducing unexpected plant downtime and costly incidence mitigation expenses.

The O\&M costs are estimated for various plants at between 60 and $70 \%$ of the overall generating cost, with fuel costs accounting for 15-30\% of the generating costs for each NPP. In the US, approximately $80 \%$ of the O\&M costs are related to labor costs. The situation is further complicated by the problem of an aging workforce and a limited supply of replacements. ${ }^{3}$ O\&M costs will continue increasing as the life of NPPs is extended beyond the initial 40 year license (about $75 \%$ NPPs are older than 20 years worldwide) due to SSC degradation caused by operating loads and environmental stressors in aging plants.

The implementation of a PHM system for a SSC consists primarily of three parts: (1) selection of SSCs to be monitored, (2) identification of failure mechanisms, including failure modes and precursors, physical degradation phenomena, and their severity; and (3) development and/or implementation of appropriate monitoring, diagnostic and prognostic method to accurately predict component operating reliability such as actual failure probability or remaining useful life (RUL). Ideally, these steps are considered simultaneously. For example, accuracy and effectiveness of a component selection in the first step will benefit from updated information on the failure probability of the component.

The selection of components to be monitored using a PHM system is based on the risk significance of a component, its expected aging degradation (failure modes and aging conditions), current operating and maintenance procedures (effect of operation, detection, and prevention of failure), and costs (maintenance costs and failure mitigation costs). ${ }^{4}$ PHM provides the means to determine RUL and select appropriate 
mitigation to ensure consistent risk, regardless of component age. The current operating and maintenance procedures are considered in the component selection process to ensure that the new PHM system is expanded beyond existing monitoring, diagnostic and prognostic activities. ${ }^{5,6,7}$ According to the nuclear industry maintenance guidelines published by the Nuclear Energy Institute (NEI) and the Electric Power Research Institute (EPRI), NPP SSCs with high risk significance measures concerning core damage frequency (CDF) are subject to rigorous maintenance rules. However, SSCs outside the scope of the maintenance rules continue to have appropriate maintenance activities performed on them. For these SSCs, the degree of maintenance attention will depend on factors such as the consequence of SSC failure on plant safety, power production, and economics.

Besides these technical aspects of component monitoring, human and organizational factors such as expertise, aging of plant personnel, and transfer of knowledge should also be considered. ${ }^{8}$

\subsection{Component Risk Significance Estimate}

\subsubsection{Risk Significance Measures}

The Fussell-Vesely Importance Measure (F-V) and risk achievement worth (RAW) are two common measures used to quantify the risk significance for each SSC (both safety related and non-safety related) in various operational decision making situations. These measures are both based on probabilistic risk assessments (PRA), and are defined below.

\section{Fussell-Vesely Importance Measure}

The F-V measures the overall percent contribution of cut sets containing a basic event of interest to the total risk. It is calculated by finding the value of cut sets that contain the basic event of interest $\left(\mathrm{x}_{\mathrm{i}}\right)$ and dividing by the value of all cut sets representing the total risk (baseline risk),

$\mathrm{FV}_{\mathrm{xi}}=\mathrm{F}(\mathrm{i}) / \mathrm{F}(\mathrm{x})$

where

$\mathrm{F}(\mathrm{i})$ denotes risk from just those cut sets that contain event $\mathrm{x}_{\mathrm{i}}$ and $\mathrm{F}(\mathrm{x})$ denotes the total risk from all cut sets. The FV value lies in the interval $[0,1](0 \%$ to $100 \%)$. For Maintenance Rule (10 CFR 50.65), NUMARC Guide 93-01 (endorsed by NRC) uses a Fussell-Vesely importance of 0.005 , i.e., $F-V>0.0005$.

\section{Risk Achievement Worth}

RAW measures the amount that the total risk would increase if a basic event's failure probability was 1 (e.g., the component is taken out of service or fails). It is calculated as a ratio between the value of the total risk with the failure probability for the basic event of interest $\left(\mathrm{x}_{\mathrm{i}}\right)$ set to 1 and the total risk (baseline risk)

$\mathrm{RAW}_{\mathrm{xi}}=\mathrm{F}(1) / \mathrm{F}(\mathrm{x})$

where

$\mathrm{F}(1)$ is the total risk with basic event $\mathrm{x}_{\mathrm{i}}$ probability set to 1 . By definition, the RAW is greater than 1 . For Maintenance Rule (10 CFR 50.65), NUMARC Guide 93-01 uses a RAW significance criterion of $2(R A W>2)$. 


\subsubsection{Risk Significant Estimation Methods}

Risk significant criteria have been established to determine which of the SSCs are risk significant and can be estimated using any of the following methods: individual plant examination (IPE); plant-specific PRA; critical safety functions (e.g., vessel inventory control) system performance review; other appropriately documented processes.

The following sources provide useful data for monitoring risk significant SSC performance for utilities: preventive maintenance (PM) program results, evaluation of industry-wide operating experience, and generic failure data.

Most of the methods identify SSCs as risk significant based on their contribution to the core damage frequency. It is also equally important to identify risk significant SSCs whose failure could result in an unacceptable release of radioactive material. Examples might include the containment spray system, containment cooling system, and valves that provide the boundary between the reactor coolant system and low pressure systems located outside containment. In addition to F-V and RAW, as described above, an $\mathrm{SSC}$ would probably be considered risk significant if it belongs to the risk significant ordered group contributing to the top $99.0 \%$ of the cumulative risk importance.

\subsubsection{Limitations of component risk significance measures}

Ranking of components based on risk significance measure is not always well-understood in terms of engineering interpretations: high risk ranking does not necessarily imply that the SSC is the dominant contributor to CDF. RAW provides indication of risk impact of taking equipment out of service, but may not capture the full impact: e.g., taking components out of service for test and maintenance may increase the likelihood of an initiating event due to human error. Risk rankings apply only to individual contributions and not to combinations or sets of contributors.

The risk significance measures do not take into account the possibility of external events or factors adversely impacting SSCs. External events include natural disasters such as the March 2011 earthquake and tsunami that had devastating effects on the Fukushima Daiichi nuclear power plant. External factors include grid power quality, which can affect the NPP during power up. Harmonics from the power grid can pass through the electronic equipment, leading to lower life span of the electronic equipment. Grid power quality can be affected by many events, including lightning strikes, power grid switching at the electric utility, and inclusion of intermittent power sources. Additionally, power quality inside the NPP can be affected by electromagnetic interference, radio frequency interference, and power surges. An Oak Ridge National Laboratory (ORNL) study by Wood et al. ${ }^{9}$ asserts that the effects of these phenomena on safety-related Instrumentation and Control (I\&C) systems in NPPs are of increasing concern, particularly as more digital technologies are adopted by NPPs.

\subsection{Limitations of Traditional Maintenance and Monitoring Approaches}

The traditional maintenance strategy relies on the use of the current safety system unavailability performance indicators. The utility must first determine which SSCs are within the scope of the Maintenance Rule by applying the predefined screening criteria. The scope of the Maintenance Rule, as defined in the NEI guideline, ${ }^{5}$ is limited to SSCs that directly affect plant operations (mostly safety related SSCs). The maintenance requirements and planning guidelines (e.g., 12-week rolling schedule) are based mainly on the technical specifications and limiting conditions for operation such as:

- Identifying SSCs important to safety based on the traditional engineering approach assuming constant component reliability over time using the train protection concept and technical specifications. 
- Limiting component out-of-service times for individual outages and combinations of component outages (not based on formal risk analysis). There is no limit on frequency of equipment outages only on duration of each outage.

- Providing guidance to work week planners on allowable maintenance/testing, thus overlooking some components (e.g., cables, structures, etc.) with historically low failure probability that might have increasing risk significance measure due to aging effects.

- Using operator engineering judgments that are limited to technical specification equipment.

\subsection{Risk-Informed Performance-based Maintenance}

The advanced risk-informed performance-based maintenance approach for NPPs is increasingly and widely accepted in the nuclear industry. Its defense-in-depth attributes and safety margins philosophy has traditionally been applied in reactor design and operation to provide multiple means to accomplish safety functions and prevent the release of radioactive material. The maintenance strategy is based on a set of risk-based performance indicators (RBPIs) and mitigating systems performance index (MSPI). The RBPIs provide performance measures whose impact on CDF and large early release frequency (LERF) can be established through a risk model or risk logic. The purpose of the MSPI is to "monitor the performance of selected systems based on their ability to perform risk-significant functions." ${ }^{10}$ As such, the new MSPI approach measures safety system performance by addressing both unavailability and unreliability. ${ }^{11}$

Two key attributes of the MSPI are the consistent treatment of both unavailability and unreliability; and the implementation of plant-specific performance thresholds. Basic reliability theory recognizes that optimum system performance is achieved when the proper amount of PM is applied. Too little PM causes the unreliability term to become unacceptably high, while too much PM drives the unreliability term to near zero but at the expense of too much downtime. In addition, the implementation of plant-specific thresholds acknowledges the large dissimilarities in design and operation of nuclear power plants, and sets the performance thresholds commensurate with the risk-significance of the varying systems and the number of component demands and failures.

Despite its effective way to account for uncertainties in equipment and human performance, the riskinformed performance-based maintenance approach has a number of drawbacks. This framework requires specification of myriad parameters whose values have not been determined due to lack of available data. The quantification of the MSPI is not transparent for some specific conditions such as: (1) multiple concurrent failures of components, (2) conditions that cannot be discovered during normal surveillance tests; and (3) failures of passive components (such as piping and heat exchangers) which are not taken into account in PRA models.

\subsection{Prognostic and Health Monitoring (PHM) Maintenance Strategy}

For longer term operation of NPPs and to optimize the preventive maintenance, the PHM maintenance strategy is one of the most effective solutions. Current state-of-the-art PHM techniques identify state of degradation in SSCs and estimate the remaining useful life based on the current operating condition. These techniques are effective but do not address concerns such as: (1) RUL estimation under changing operating (dynamic) conditions, (2) prognosis/diagnosis with missing sensor data or misspecification of data in a noisy environment, (3) identification of multiple concurrent failures of components; and (4) fusion of in-site surveillance information with online monitoring data.

Advanced PHM techniques can address some of these concerns by taking advantage of data fusion techniques. A data fusion technique enables integration of signatures from different sensor types 
(temperature, vibration, acoustic, current) installed on an SSC and data from in-site surveillance to identify a unique state of degradation. An early warning can be established for proactive maintenance and RUL estimation. Data fusion techniques can also be used to integrate decisions obtained from PHM system and in-site surveillance on the proactive Maintenance Rule. Henceforth, data fusion techniques will assist in making dynamic maintenance strategies for NPPs which in turn will lead to reduction in maintenance cost.

Therefore, advanced PHM techniques will have two-fold benefits over the current state-of-the art approach. First, they provide early warning on the state of degradation of SSCs in NPPs and/or their RUL, thus increasing SSC's reliability. Second, they reduce maintenance costs by allowing a dynamic maintenance strategy for NPPs.

\subsection{Component Selection for Advanced PHM System}

\subsubsection{PHM system Component Selection Criteria}

The goal of implementing a PHM system in an NPP is to provide additional plant-specific component operating reliability (or performance) to ensure highest effectiveness of the advanced risk-informed performance-based maintenance strategy and to overcome its limitations with the help of modern monitoring instrumentations and state-of-the art prognostic and diagnostic technologies. The criteria for selection of components to be covered by the PHM system are based on:

- Risk impact of SSC availability and reliability at each plant

- Plant specific PRA success criteria for SSCs incorporating component aging effects (e.g., aging failure modes and effect analysis) rather than design basis criteria

- Component risk significance measure with emphasis on non-safety related components (see definition in Section 2.5.2) to avoid conflict with licensing requirements

- Aging sensitivity of the SSC

- Economical effectiveness.

\subsubsection{Component Selection Methods}

Methods for selection of an appropriate component for the PHM system implementation in NPPs are probabilistic techniques, analysis of operating experience, and expert judgment. The first attempt to select an appropriate component is based on probabilistic techniques; thus the main selection criterion is the risk significance (product of failure probability and consequence) of the component on the safe operation of the plant. However, the component risk significance measures do not fully represent the contributing impact on plant performance; therefore, the final selection decision should be confirmed by expert judgment and operating experience. The NPP SSCs are divided into two categories: (1) safety-related; and (2) non-safety related SSCs, and components, as follows ${ }^{6}$ :

1. Safety-related SSCs - SSCs that are relied upon to remain functional during and following design basis events. This ensures the integrity of the reactor coolant pressure boundary, the capability to shut down the reactor and maintain it in a safe shutdown condition, and the capability to prevent or mitigate the consequences of accidents that could result in potential offsite exposure.

2. Non-safety related SSCs - SSCs that are relied upon to mitigate accidents or transients or are used in plant emergency operating procedures; SSCs whose failure could prevent safety-related SSCs from fulfilling their safety-related function; or SSCs whose failure could cause a reactor scram or actuation of a safety-related system. 
The component selection process consists of following steps:

1. Study the component reliability (failure probability) and safety status (safety related or non-safety related) for each component. When possible, component reliability should account for aging effects. This requires excessive amounts of data (including reliability data for NPPs, similar components from other industries, and from accelerated aging reliability tests) and extensive research, which is not within the scope of this report. Knowledge about physical phenomena contributing to the material degradation process would help increase accuracy of component reliability estimation, particularly for long-term passive components.

2. Rank the SSCs by their risk significance measure as calculated from the PRA risk significance results for actual NPPs. SSCs are considered risk significant when their risk significance measures are greater than predefined critical values: F-V $>0.005$ or/and $\mathrm{RAW}>2$.

3. Select components, preferably non-safety related, with high risk significance measure, high failure probability, vulnerability to external factors, and also high feasibility of monitoring. These component selection criteria maximize the value of the proposed PHM system, increasing the chance of successful implementation.

4. Assess the economical benefit of the proposed PHM system using best knowledge of plant operation common practice.

\subsubsection{Component Risk Significance Measure Estimation}

Safety functions of all safety related and non-safety related SSCs are addressed by the Maintenance Rule. ${ }^{5}$ The functions that cause SSCs to be within the scope of the Maintenance Rule are identified and documented. Traditionally, the risk of the SSC failure on intended function involves both the likelihood of an undesired event (or failure probability caused by component failure) and severity (magnitude) of the consequences. In the PRA framework, the component failure risk representing the consequence magnitude per unit of time can be calculated as follows:

Risk $=$ Frequency $($ Probability $) *$ Consequences

where Frequency is the number of occurrences of the event of interest in a defined interval of time and Consequences denotes the consequence magnitude of a single event. The most risk significant component has the largest product of frequency and consequence. From the perspective of selecting a component for PHM coverage, the component reliability such as failure rate should be considered along the significance measure representing the impact of component failure on overall plant risk.

\subsubsection{Assessment of the Economic Benefit of the Proposed PHM System}

Figure 1 depicts the economical aspect of implementation of the PHM system at the component level. Let $C$ denote the cost associated with the implementation of the proposed PHM system. In addition to important safety benefits (e.g., reducing public perception of risk, minimizing safety impact, and increasing reliability), implementation of PHM introduces operational benefits (e.g., avoiding unplanned plant shutdown, decreasing planned plant shutdown duration, increasing flexibility in maintenance scheduling). This leads to improved planning of inspection and repair activity, higher quality maintenance, shorter and less complex outages, fewer unexpected discoveries during outages, elimination of unnecessary tests and reduced radiation exposure, resulting in lower O\&M costs.

The primary economical benefit of implementing a PHM system arises from the reduction in component failure probability due to timely component inspection, repair, and/or replacement. Specifically, $\mathrm{p}_{\mathrm{c}}$ denotes the component failure probability without a PHM system and $\mathrm{p}_{\mathrm{m}}$ denotes the component failure probability with the PHM system such that $\mathrm{p}_{\mathrm{m}}<<\mathrm{p}_{\mathrm{c}}$. 
In general, NPP safety analysis of a component (safety-related or non-safety related) is performed in terms of CDF. Let $\pi$ be the conditional probability of core damage given that a component failure occurs with probability $\mathrm{p}_{\mathrm{c}}$. Let $\pi_{m}$ be the conditional probability of core damage after PHM implementation given that a component failure occurs with probability $\mathrm{p}_{\mathrm{m}}$, such that $\left(\pi>>\pi_{m}\right)$. The mitigation cost associated with the plant specific failure mode (for example, CDF) is $\boldsymbol{x}$. Using Eq. 1, the economical benefit (or saving) of the proposed PHM system would be the difference in expenses with and without the PHM system, and can be estimated by the expression $\left(\pi-\pi_{m}\right) \cdot x$. According to this expression, the components with high original failure probability and high risk significance measure to the plant pose higher financial risk, thereby making them good candidates for PHM system coverage. As the plant ages, the long term components may become less reliable, thus increasing their risk significant measure and subsequently increasing plant failure probability. The mitigation expense $(\boldsymbol{x})$ includes not only the cost of component replacement but also includes additional expenses incurred due to plant downtime, evacuation, emergency systems activation, and mitigation of radioactive releases.

Additional economical benefits arise from the reduction of component maintenance costs due to fewer inspections, tests, and repairs of SSCs. This financial savings, denoted by $\boldsymbol{x}_{m}$, is plant-specific and can be estimated accordingly.

The decision to include a component in the PHM system coverage is financially beneficial when the overall economical benefit is greater than the cost of the PHM system:

$$
\left(\pi-\pi_{m}\right) \cdot x+x_{m}>C
$$

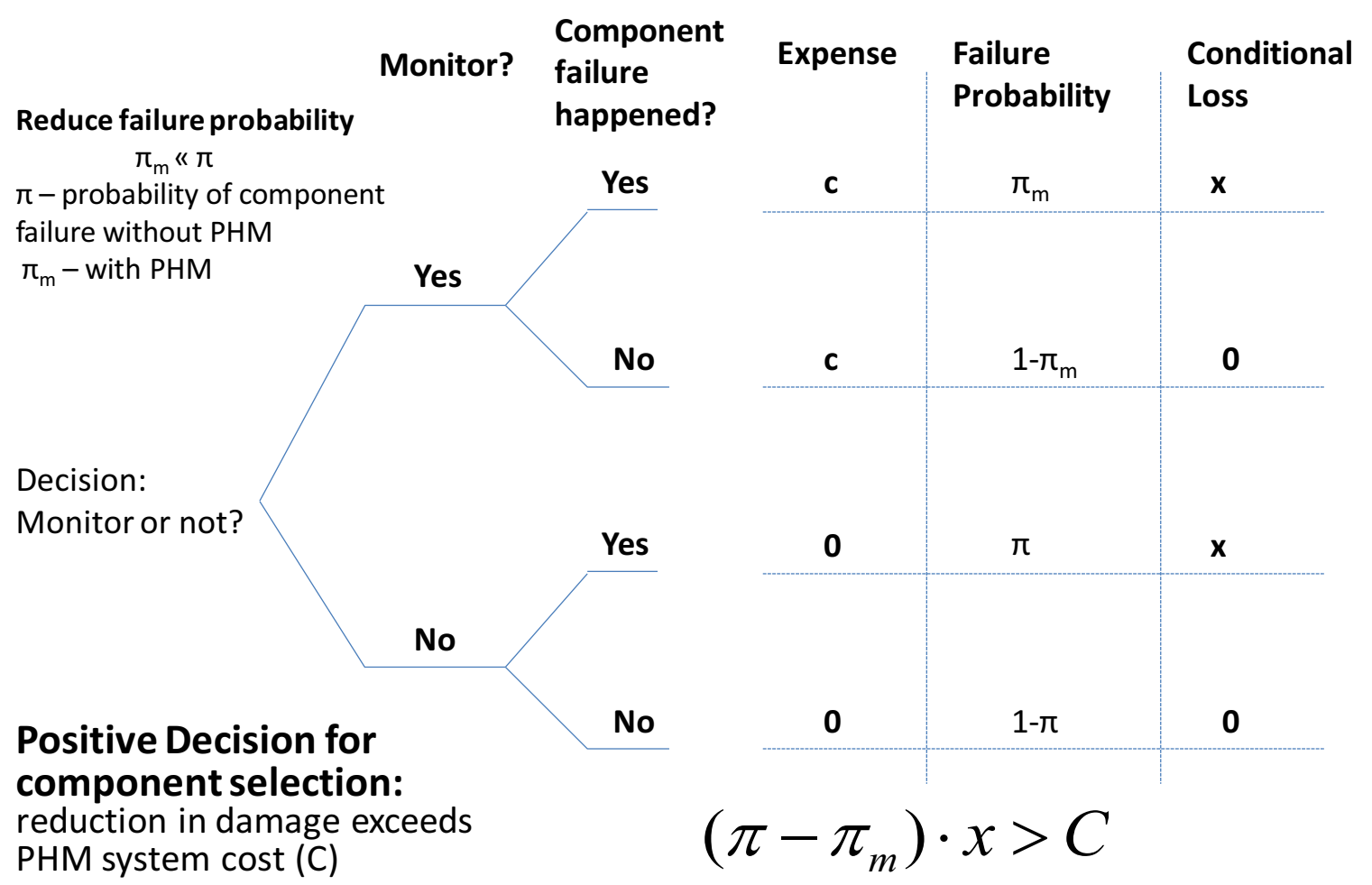

Figure 1. Outcome of component selection decision for implementation of PHM system based on reduced plant failure probability. 
Table 1 presents a sample list of NPP SSCs as a function of their risk significance measure together computed using INL's PRA software SAPHIRE.

Table 1. Categorization of NPP SSCs based on risk significance measures and safety status.

\begin{tabular}{|c|c|c|c|c|}
\hline $\begin{array}{l}\text { Non-Risk Significant SSCs } \\
(\mathrm{F}-\mathrm{V}<0.005, \mathrm{RAW}<2.0)\end{array}$ & $\begin{array}{c}\text { Risk Significant SSCs } \\
(\mathrm{F}-\mathrm{V}>0.005, \mathrm{RAW}>2.0)\end{array}$ & $\begin{array}{c}\text { Probability } \\
\text { of Failure } \\
\left(p_{f}\right)\end{array}$ & $\mathrm{F}-\mathrm{V}$ & RAW \\
\hline \multirow{17}{*}{$\begin{array}{l}\text { Transformer } \\
\text { Unpressurized External Tank } \\
\text { Engine Driven Fire Pumps } \\
\text { Offsite Power } \\
\text { Turbine By-Pass Valves } \\
\text { Turbine Building Closed } \\
\text { Coolant Water System }\end{array}$} & \multicolumn{4}{|l|}{ Safety Related SSCs } \\
\hline & Isolation Valves $^{*}$ & $1.20 \mathrm{e}-03$ & $3.84 \mathrm{e}-02$ & 31.4 \\
\hline & Reactor Vessel & $1.00 \mathrm{e}-07$ & $1.43 \mathrm{e}-05$ & 144 \\
\hline & Control Rod Drive & $2.50 \mathrm{e}-07$ & $2.34 \mathrm{e}-06$ & 10.3 \\
\hline & Trip System & $3.80 \mathrm{e}-07$ & $3.56 \mathrm{e}-06$ & 10.3 \\
\hline & Hydraulic Control Unit ${ }^{*}$ & $1.10 \mathrm{e}-07$ & $1.02 \mathrm{e}-06$ & 10.2 \\
\hline & Hydraulic Control Unit Valve ${ }^{*}$ & $1.70 \mathrm{e}-06$ & $1.59 \mathrm{e}-05$ & 10.3 \\
\hline & Diesel Generators & $3.29 \mathrm{e}-04$ & $9.11 \mathrm{e}-03$ & 3.82 \\
\hline & Service Water Supply & $2.20 \mathrm{e}-01$ & $9.98 \mathrm{e}-01$ & 4.54 \\
\hline & Suppression Pool Strainer & $2.12 \mathrm{e}-03$ & $4.86 \mathrm{e}-06$ & 66.7 \\
\hline & $\begin{array}{l}\text { Emergency Feedwater Motor } \\
\text { Driven Pump }\end{array}$ & $6.04 \mathrm{e}-3$ & $1.99 \mathrm{e}-02$ & 15.3 \\
\hline & HPCS Pumps & $1.50 \mathrm{e}-03$ & $1.63 e-03$ & 2.03 \\
\hline & \multicolumn{4}{|l|}{ Non-Safety related SSCs } \\
\hline & $\begin{array}{l}\text { Service Water Supply Pumps } \\
\text { (Secondary System) }\end{array}$ & $2.20 \mathrm{e}-01$ & $9.98 \mathrm{e}-01$ & 4.54 \\
\hline & Instrument Nitrogen System & $1.00 \mathrm{e}-02$ & $3.18 \mathrm{e}-01$ & 22.5 \\
\hline & $\begin{array}{l}\text { Battery (Secondary System: } \\
\text { Back-up Power Source) }\end{array}$ & $5.89 \mathrm{e}-04$ & $1.17 \mathrm{e}-05$ & 3.20 \\
\hline & $\begin{array}{l}\text { Battery Chargers (Secondary } \\
\text { System: Back-up Power Source) }\end{array}$ & $1.99 \mathrm{e}-08$ & $1.09 \mathrm{e}-06$ & 54.8 \\
\hline
\end{tabular}

To synchronize with industry existed monitoring activities, ${ }^{5,6,7}$ the following components are primarily selected for proposed PHM system:

\section{High Risk Significant, Safety Related Components}

1. Pump/Motor for Auxiliary Feed-water System: Due to its important and risk-critical function in plant operation, this component is often fully instrumented and monitored to ensure safe operation. Furthermore, this component monitoring is extensively studied by nuclear industry. For example, an EPRI technology innovation program on the application of prognostics for the power industry ${ }^{6}$ focused on surveying the key failure modes and identifying the most appropriate prognostic method to predict its RUL. Although state-of-art diagnostic and prognostic technologies have been applied to 
pumps and motors in other industries, there are still ways to improve the implementation of a modern PHM system for this critical component in NNPs. The following steps are proposed:

a. Review existing failure modes from previous studies in the industry organizations such as NEI, EPRI, and universities

b. Collect historical monitoring data (temperature, pressure, vibration, acoustic etc.) from the pump motor in healthy and degrading conditions

c. Apply the pattern recognition methodology to:

(1) extract unique feature related to certain failure mode

(2) find the optimum set of weights to combine multiple monitoring outputs into one response indication of failure probability

(3) validate failure predictability of the indication on new set of data

d. Apply these findings to improve accuracy and effectiveness of the existing pump/motor monitoring system.

2. Reactor Core: The core in a reactor vessel is supported at the bottom by lugs. Vibration caused by the vanes of the reactor coolant pump's impeller, occurs primarily at the ,vane passing frequency', which can be close to the resonant frequency of the core barrel. That may cause motion of the reactor vessel as the lugs wear out. Core barrel motion can be detected from the changes in the outputs of power range nuclear detectors, but is typically monitored at specified intervals rather than continuously. The Power Spectral Density (PSD) is used to determine the amplitude and phase angle of changes in output signals among the power range detectors that surround the core. Another important phenomenon that can be monitored via PSD is the power distribution shift resulting from a dropped control rod. The online monitoring system along with diagnosis techniques will allow realtime collection of data and provide early warning on any change in the PSD profile compared to historical monitoring data using advanced pattern recognition techniques.

3. Diesel Generator Engines. This safety related component provides onsite and offsite power for pumps in primary and secondary plant systems, specifically in case of loss of offsite power. Even though it does not directly affect plant safety in normal condition, its safety critical function and failure consequences in emergency situation make it risk significant for NPPs. Because of its infrequent use, the Maintenance Rule requires periodic testing, (operating the diesel generator in a test mode with no load, and inspecting it to ensure it will function as intended when needed. Some of the common failure modes investigated includes [1] cylinder pressure and vibration, [2] fuel oil pumps pressure and vibration, [3] lubricating oil temperature, etc.). Degradation of the diesel engine and its supporting system can be caused by aging, even with very little wear and tear. Dynamic condition-based inspection and testing would be more effective and economical. The trend observed from historical testing and inspection data can be used to seek an optimal maintenance schedule. The prognosis feature of an advanced PHM system can be used to accurately estimate the RUL to avoid unexpected failures.

\section{High Risk Significant, Non-Safety Related Components}

1. Transformers. Because of its non-safety related status and low perceived failure probability, the transformers are not the focus of rigorous Maintenance Rules. However, as per manufacturing specifications, the probability of failure is $50 \%$ within its expected lifetime of 30 years when operating at full load. Any change in the operating condition (e.g., low load or high load) decreases the expected lifetime a transformer. Unexpected failures of a transformer have following impacts: (1) safety threat, (2) long unplanned downtime, and (3) high replacement cost (generally higher than a monitoring cost). 
The operation of a transformer is affected by the following failure modes: (1) reduction in dielectric and thermal strength of insulations due to partial discharge, (2) reduction in electrical insulation provided by oil contamination or electrical leakage inside the transformer; and (3) dissolved gases in oil, etc. To minimize the failure rate and to avoid unexpected failure, online monitoring and diagnosis/prognosis techniques can provide early warning on the degradation state of the transformer. The PHM maintenance strategy discussed earlier is based on data fusion techniques that can be used to identify the type of test to be conducted on transformers during scheduled maintenance. 


\section{DIAGNOSIS AND PROGNOSIS TEST FACILITIES AND DATA REPOSITORIES}

Several available data sources were identified corresponding to common failure modes in NPP rotating equipments (active components), including gearbox failure, bearing failure, pump cavitation, and battery discharge. These data sources provide a basis to test the conceptual design of prognosis-based maintenance at the component level. The disjointed nature of the data sources prevents complete subsystem/system prognosis. One of the possible approaches to address the limitation is to develop a subsystem simulation tool that includes rotating components and that can help to validate the simulated behavior characteristics using available data sources.

Potential data sources considered included national laboratories, government resources, universities, private companies, and professional societies. Identified sources are summarized in the subsections.

\subsection{National Laboratories}

\section{Oak Ridge National Laboratory (ORNL)}

The High Flux Isotope Reactor (HFIR) at ORNL is one of the potential DOE facilities that has been used for research and development of a conceptual design of Prognostic Health Monitoring (PHM) system. ${ }^{12}$ Vibration signals were collected from different secondary pumps and rotating components of the HFIR reactor for online monitoring.

\subsection{Government Facilities}

\section{National Aeronautics and Space Administration (NASA)}

The Advanced Diagnostics and Prognostics Test Beds (ADAPT) at NASA Ames Research Center is a facility designed to perform diagnosis and prognosis of batteries, actuators, and electronic components. ADAPT has several test beds to investigate different aspects of diagnostic and prognostic technologies. In particular, ADAPT has developed a battery prognostic framework. The framework and the data set on batteries are useful to track and predict the discharge of risk-significant battery in aging nuclear power plants. In addition, NASA Glenn Research Center has a Gearbox Test facility.

NASA's prognostics data repository is a collection of data sets that have been donated by various universities, agencies, or companies. The data repository focuses exclusively on prognostic data sets, i.e., data sets that can be used for development of prognostic algorithms. Mostly these are time series data from some nominal state to a failed state.

NASA's prognostic repository includes a bearing data were generated by National Science Foundation Industry/University Cooperative Research Center (NSF I/UCR) Center of Intelligent Maintenance Systems (IMS) with support from Rexnord Corp. in Milwaukee, MI. ${ }^{13}$ Four bearings were installed on one shaft. The rotation speed was kept constantly at 2000 RPM. A 6000-lb radial load was placed onto the shaft and bearing by a spring mechanism. All bearings were force lubricated. On each bearing two PCB 353B33 High Sensitivity Quartz ICP Accelerometers were installed for a total of 8 accelerometers (one vertical $\mathrm{Y}$ and one horizontal $\mathrm{X}$ on each). Figure 2 below shows the test rig and illustrates sensor placement. All failures occurred after exceeding designed life time of the bearings, which is more than 100 million revolutions. 


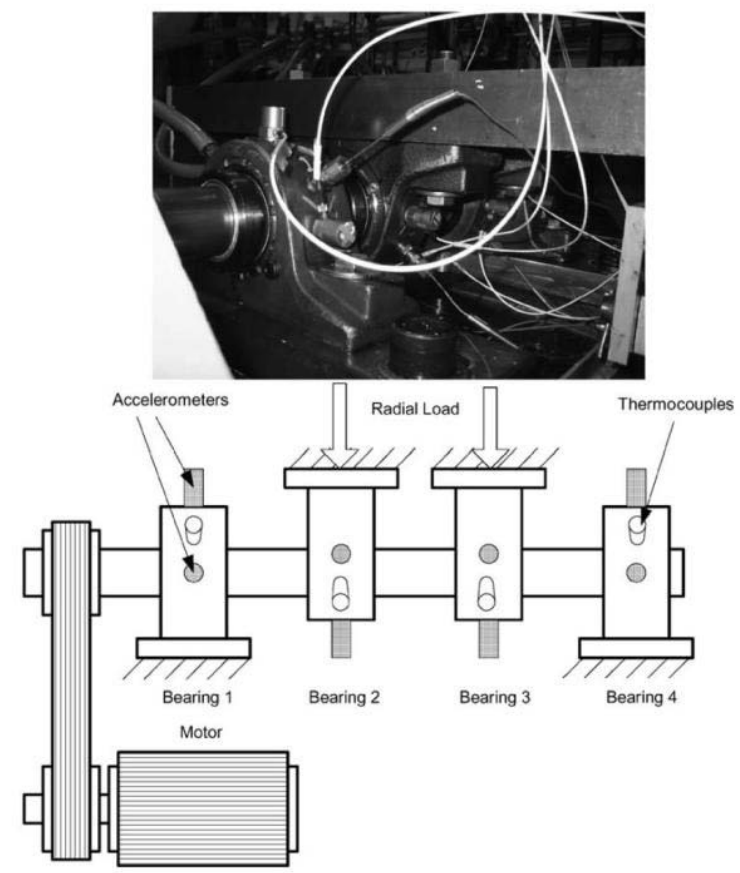

Figure 2. Bearing test rig and sensor placement illustration. ${ }^{14}$

\subsection{Universities}

\subsubsection{Pennsylvania State University Applied Research Laboratory}

The pump test facility at Applied Research Laboratory (ARL) at Pennsylvania State University has been designed to accommodate a wide range of operating condition, pump configuration, and measurement system to measure pump hydrodynamic performances. The pump test facility is shown in Figure 3.

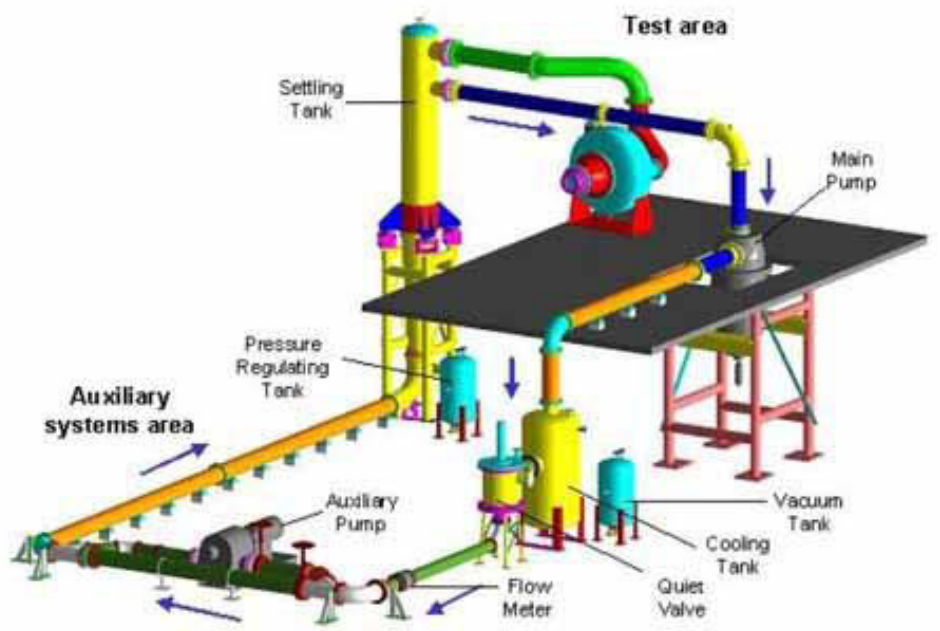

Figure 3. Pump Loop Facility at Pennsylvania State University. ${ }^{15}$ 
ARL has agreed to share the gearbox data set collected under grant N00014-95-1-0461, sponsored by the Department of Navy, Office of the Chief of Naval Research.

\subsubsection{The University of Tennessee Knoxville}

Accelerated degradation test beds at the University of Tennessee (as seen in Figure 4-Figure 6) can be used to develop and validate prognostic algorithms. Specifically:

1. The test bed in Figure 4Figure 4 is a pump accelerated degradation facility developed for an EPRI prognostic project

2. The test bed in Figure 5 is a heat exchanger accelerated degradation test bed developed for a Nuclear Engineering Education Research (NEER) project

3. The test bed in Figure 6 is a rotating equipment degradation test bed initially developed for generator accelerated degradation testing for a Navy funded Small Business Innovation Research (SBIR) and then redeveloped for an EPRI project on transient prognostics.

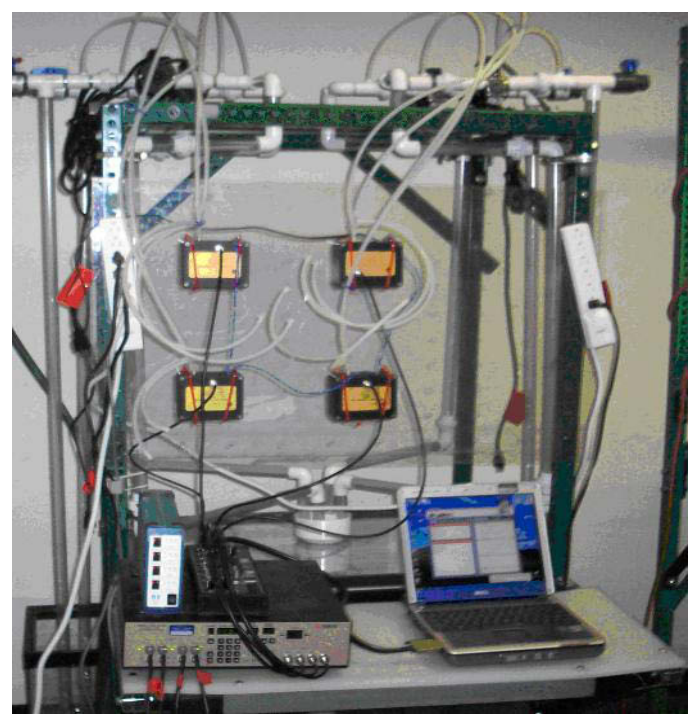

Figure 4. Accelerated pump degradation test bed.

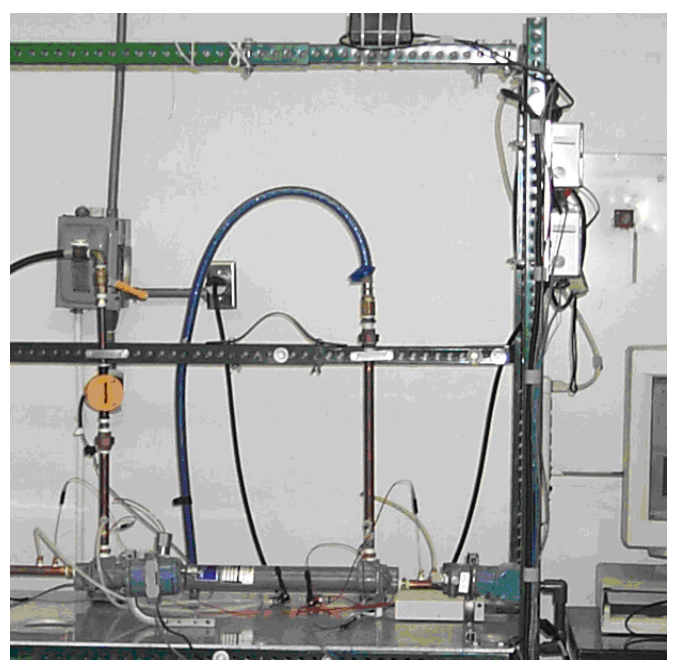

Figure 5. Accelerated heat exchanger test bed.

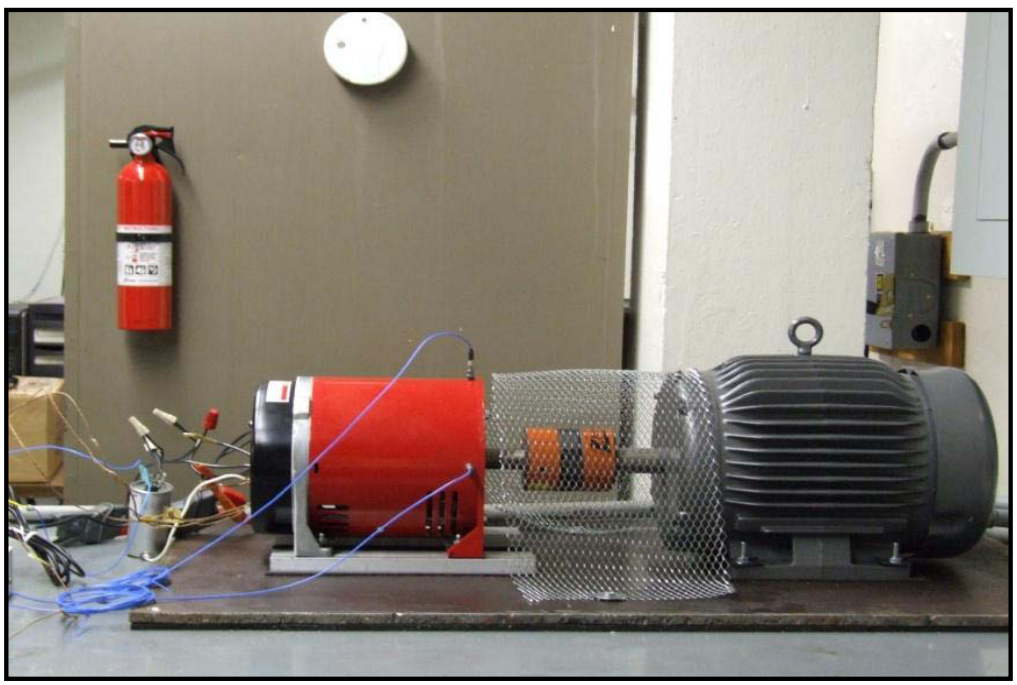

Figure 6. Accelerated motor test bed. 
A fully instrumented multivariate experimental flow control loop in Figure 7 was developed to test the performance of control and online fault monitoring methods for several projects including a three year NERI-C entitled, "Advanced Instrumentation and Control Methods for Small and Medium Reactors with IRIS Demonstration." 16

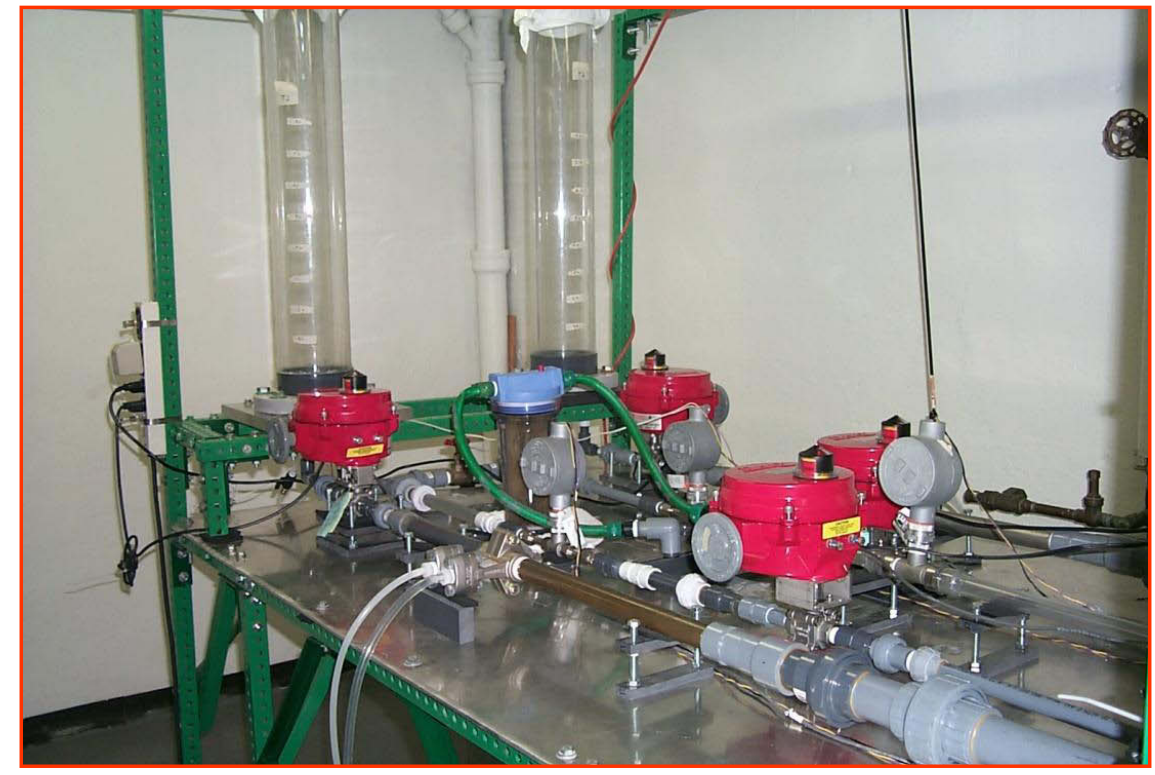

Figure 7. Experimental flow loop test bed.

The test beds identified are outfitted with state-of-the-art data acquisition systems consisting of antialiasing filters and National Instruments data acquisition systems, LabVIEW processing and visualization software, current transformers, thermocouples, flow meters, accelerometers, etc. Other specialized maintenance equipment for functions such as winding resistance testing is also available. Degradation data collected during other projects can be utilized to the highest extent possible for new prognostic projects.

The University of Tennessee, Knoxville is willing to collaborate and share the data set.

\subsubsection{The University of Texas, Arlington}

The Advanced Controls and Sensor Group at The University of Texas, Arlington has a test facility to measure data from rotating components (such as motors, fans, turbines) for intelligent diagnosis and prognosis research. An effort is directed towards gaining permission to different data sets collected by the group at The University of Texas, Arlington.

\subsubsection{Georgia Technical University: System Monitoring and Prognostic Lab}

The experimental test bed at Georgia Technical University (Figure 8) consists of: two wireless crossbow vibration sensors to continuously capture the vibration signals, a hydraulic system and a hydraulic cylinder to load each test bearing, and a digital National Instruments data acquisition and control system with interface programmed in LabVIEW. 


\section{Prognostics of Mechanical Applications}

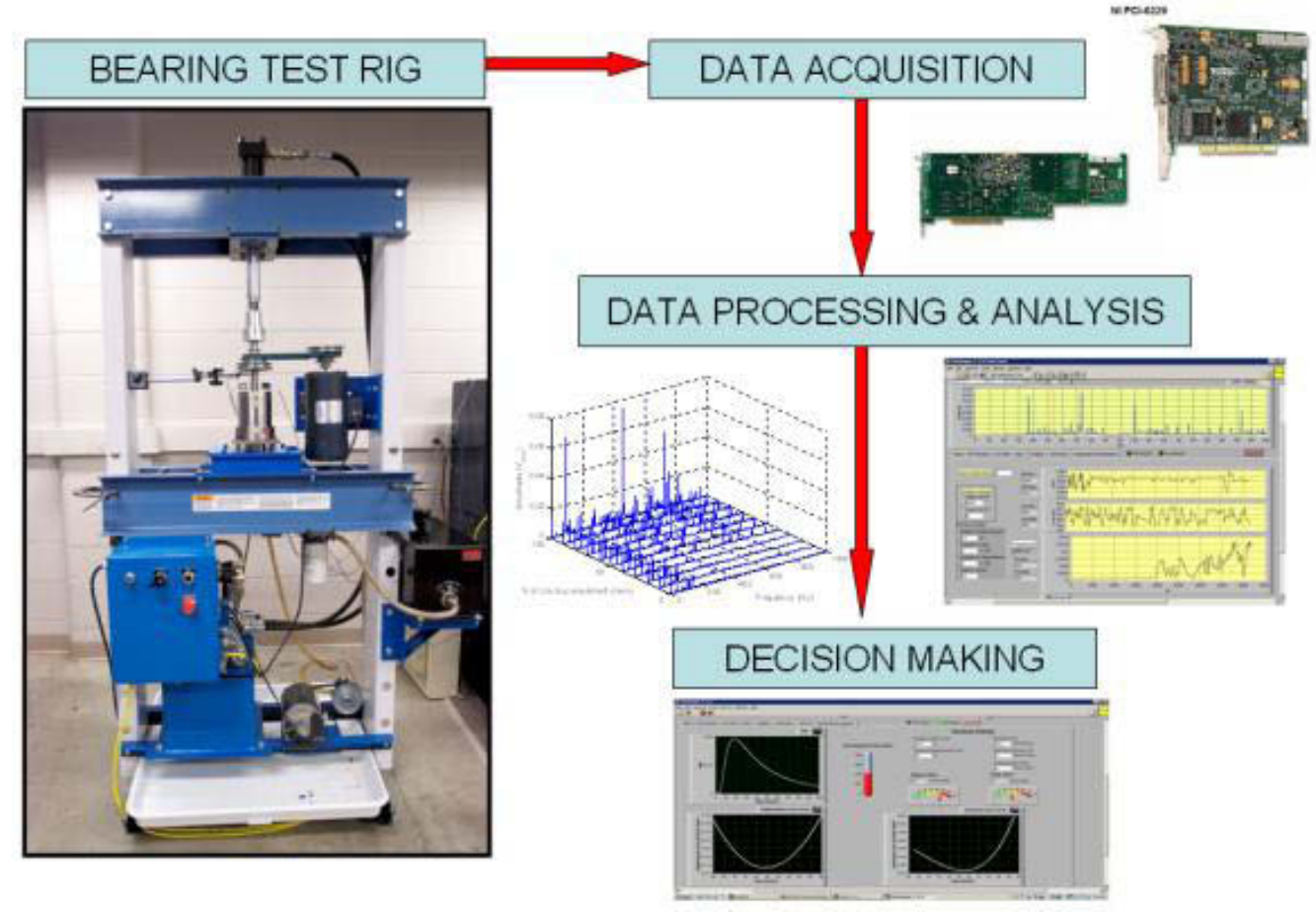

Figure 8 . Bearing testing setup to emulate degradation in rotating machinery.

\subsection{Industry}

Doble Engineering offers diagnostic instruments, services, and a library of valuable performance (diagnostic) data on more than 100,000 types of components via Doble Resource Library. Doble also has a laboratory service available to perform different types of accelerated aging and diagnostics experimentations.

Electrical Power Research Institute (EPRI) provides access to an online preventive maintenance database. The database includes pump and bearing data, information from plant data historians, and results of operator inspections. The data are part of EPRI's Asset Failure Signature (AFS) database which is intended to act as a repository to catalog and store asset fault information. Although current AFS database is neither comprehensive nor complete but still can be used for diagnosis and prognosis of certain risk significant selected SSCs. ${ }^{7}$

\subsection{Professional Societies}

\subsubsection{Prognostic and Health Monitoring Society (PHM Society)}

The PHM Society is a non-profit organization that provides free and unrestricted access to PHM knowledge that includes data sets, documents, research publications, and discussions. Available data sets include a gearbox data set that is representative of generic industrial gearboxes. ${ }^{17}$

The gearbox data was sampled synchronously from accelerometers and were collected at 30, 35, 40, 45 , and $50 \mathrm{~Hz}$ shaft speed under low and high loading. A total of 560 samples were collected. Figure 9 represents the experimental setup used to collect the data. The experimental set up includes Endevco 
$10 \mathrm{mv} / \mathrm{g}$ Accel, acquisition system. An example of gear faults tested in the experiment is shown in Figure 10.

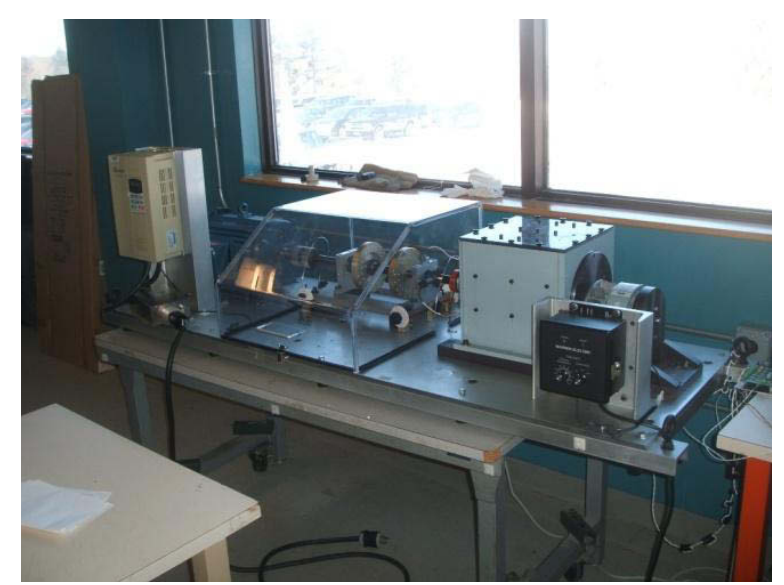

Figure 9. Experimental setup for gearbox degradation testing.

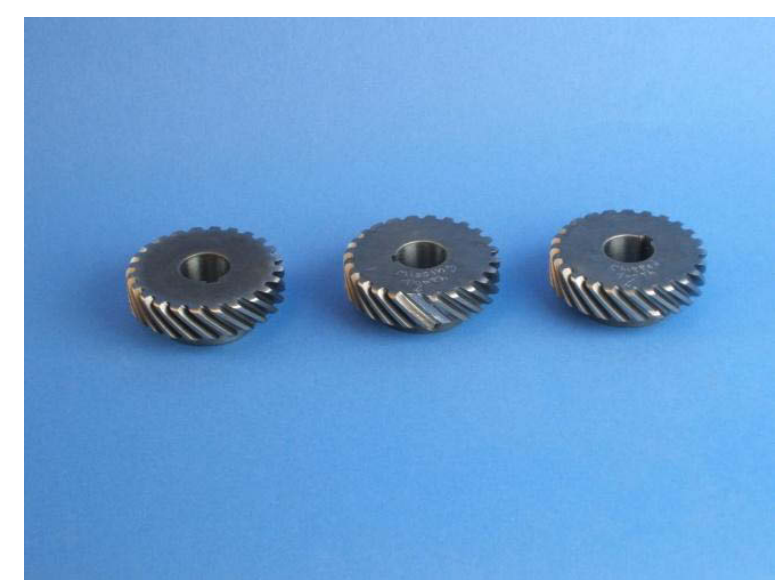

Figure 10. An example of gear faults. Left to right: normal, missing tooth, and chipped tooth.

\subsection{Simulation}

A simulation tool can be used to simulate the operational profile of an active component under normal operation condition. By using a fault injection system, faults can be injected into the operational profile of an active component. Some of the tools that can be used to simulate the operation of motors, pumps, valves, and batteries are listed below:

- Simulink is a MATLAB ${ }^{\circledR}$ based simulation environment that can be used to simulate the operation of different types of pumps, motors, and valves by proper selection of parameters as per model and specification requirements.

- PumpLinx ${ }^{18}$ is a software tool used to accurately model flow and cavitations in pumps and motors under different operating conditions. PumpLinx is based on the latest numerical techniques that enable it to accurately model high volume fractions of vapor and/or non-condensable gas (as part of Cavitation Models). 


\section{SUMMARY}

An effective implementation of the PHM system in NPPs requires careful selection of risk significant SSCs and a failure mode degradation library. A systematic procedure is presented to select potential SSCs (both safety related and non-safety related) for PHM system based on quantified risk significance for each SSC using the F-V Importance Measure and the RAW measure. A framework demonstrating the economic benefit associated with the implementation of the PHM system is also presented. A failure mode degradation library based on data received from various national laboratories, universities, agencies, and industries is proposed in lieu of building a scale-facility at INL. The library will serve as a platform to demonstrate the effectiveness of PHM system in NPPs. 


\section{REFERENCES}

1. Bond, L. J., 2007, NDE to Prognostics - a review, Joint NRC and DOE Workshop on US NPP Life Extension R\&D Issues, PNNL, February 21, 2007.

2. Rusaw, R, B. Hollinghaus, and R. Bickford, 2011, Prognostics and Health Management for Long Term Reliability of Nuclear Power Plant Assets, EPRI, INL meeting May 24-25, 2011.

3. Bond, L. J., and R.M. Meyer, 2011, Online Monitoring to Enable Improved Diagnostics, Prognostics and Maintenance, ICI (ISOFIC, CSEPC, ISSNP), Daejeon, Korea, August 21-25, 2011.

4. Lybeck, N, et al., 2011, "Lifecycle Prognostics Architecture for Selected High-Cost Active Components," INL/EXT-11-22915, Revision 0, August 3, 2011.

5. NEI, "Industry Guideline for Monitoring the Effectiveness of Maintenance at Nuclear Power Plants," NUMARC 93-01, Rev. 4, 2010.

6. EPRI, TR-112500, 2000, "Guidelines for Application of the EPRI Preventive Maintenance Basis," 2000.

7. EPRI, 2009, "Program on Technology Innovation: Prognostic Application for the Power Industry," $1018245,2009$.

8. Simola, K., 1999, "Reliability Methods in Nuclear Power Plant Ageing Management," Espoo, Finland : s.n., Ph.D. Dissertation, VTT Publication 379, 1999.

9. Wood, R. T., et al., 1999, "Electromagnetic Compatibility in Nuclear Power Plants," International Conference of Future Nuclear Systems, Jackson, WY. OSTI ID: 7434; Legacy ID: DE00007434; ORNL/CP-103297, 1999.

10. Hamzehee, H. G., et al., "Risk-Based Performance Indicators: Results of Phase 1 Development," NUREG-1753, 2002.

11. Dube, D. A., et al., Independent Verification of the Mitigating Systems Performance Index (MSPI) Results for the Pilot Plants.

12. Hashemian, H. M., 2011, "Wireless Sensors for Predictive Maintenance of Rotating Equipment in Research Reactors," Annals of Nuclear Energy, Vol. 38, pp. 665-680, 2011.

13. Center for Intelligent Maintenance Systems, 2011, http://www.imscenter.net/, accessed September 26, 2011.

14. Qiu, H, Lee, J. and Lin, J., 2006, "Wavelet Filter-based Weak Signature Detection Method and its Application on Roller Bearing Prognostics," Journal of Sound and Vibration, Vol. 289, pp. 1066-1090, 2006.

15. Pennsylvania State University Applied Research Laboratory, Pump Loop Facility, http://www.arl.psu.edu/facilities/pump loop.html, accessed September 26, 2011.

16. Hines, J. W., et al., 2011, “Advanced Instrumentation and Controls Methods for Small and Medium Reactors with IRIS Demonstration," Report No. DE-FG07-07ID14895/UTNE/2011-3 NERI-C, 2011.

17. PHM Society, 2009, "2009 phm Challenge Competition Data Set," http://www.phmsociety.org/references/datasets, accessed September 26, 2011.

18. Simerics, Inc., 2011, "PumpLinx," http://www.simulinx.com/pumplinx software.html, accessed September 26, 2011. 